\title{
El exilio hecho escritura Aprender en la errancia
}

\section{S. Alonso}

Universitat Autònoma de Barcelona

\section{Sumario}

M ilan Kundera: el exilio en la novela

Estar en otra parte
Condición judaica en la patria escrita Aprender en la errancia

C reo que en cierto modo todos los escritores experimentan la situación del judío, porque cada escritor, cada creador, vive en una especie de exilio. Y para el propio judío, el judío que vive su condición de judío, el libro se ha convertido no sólo en el lugar donde puede encontrarse a sí mismo con mayor facilidad, sino también en el sitio donde puede encontrar su verdad ${ }^{1}$.

Conocemos la prescripción de que un escritor debe encontrar la soledad consigo mismo y con su mundo para componer un relato. Pocos ponen en duda este mito: para escribir se precisa, además de enseres y destreza, retiro. Ausentarse de su mundo cotidiano para convertirlo en escritura. I dealmente, le identificamos como aquel ser solo, oscuro y apartado de su entorno, repudiado por los suyos². Según la tradición romántica, debe haber nacido introvertido o convertir su personalidad en autorreflexión y contemplación frente a la vida. El trabajo remunerado embrutece la casta creatividad de la composición literaria. Este distanciamiento, aunque el escritor no haya pisado nunca tierras extranjeras, es en cierto modo una exigencia. Su libertad existencial y creativa reside en la obligación de exiliarse, a veces tan sólo momentáneamente, de su mundo.

1. Auster, P. (1992). «Providence. Una conversación con Edmond Jabès», en El arte de hambre. Barcelona: Edhasa, p. 124-125.

2. El concepto del escritor romántico lo vemos resumido en GASS, W. «T he philosophical Significance of Exile», en G LAD, J. (ed.) (1990). Litterature in exile. Londres: D ukeU University Press, p. 1:

«T he idea of exile must be a highly romantic one, consisting principally of poets in Paris passing their time in cafés and having their saucers counted.» 
El exilio puede manifestarse de muchas maneras ${ }^{3}$, desde la huida física mediante el viaje o la desaparición de los espacios cotidianos; el abandono del pensami ento compartido, a través del silencio y la soledad ante disputas incoherentes con las creencias de uno mismo, o el retiro del compromiso afectivo, escondiéndose tras la máscara de la mentira emocional. El mero hecho de vivir y sentir nuestro entorno nos hace víctimas potenciales del asalto del exilio como expulsión, como emigración o como metáfora ${ }^{4}$. Todos ellos formas del exilio. $Y$ todas ellas, en menor o mayor medida, posibles de ser vividas.

Exile, I believe, exists in numerous forms, although ultimately it is the basic condition of all men ${ }^{5}$.

La distancia existencial como injusta reclusión se transfiere en un esfuerzo de readaptación en presencia de una nueva condición no elegida, pero sí obligada, y una esperanza de presunto retorno en un futuro hipotético. Se exige una fe callada de reconciliación con lo pasado que, a la vez, conlleva una conciencia de reposo irrecuperable. El diálogo interior, sin habla comunicativa, refleja un interés de resguardo, de defensa ante un posible ataque externo. Aún así, este silencio puede acontecer prisión como forma radical de exilio, sin salida de su posición frente a su mundo cotidiano y como condición sine qua non de su existencia o, por contra, como evasión, como necesidad de escape y de no enfrentamiento con las situaciones acaecidas en el mundo de la vida6. Aflicción y añoranza. Ambos exilios (el de prisión y el de evasión) implican sentimientos contradictorios y, sin embargo, complementarios. Exclusión e inclusión. N ostal gia y esperanza. D olor y riqueza. Son sentimientos dinámicos, con fuerte experiencia de encierro pero, también, de ilusión hacia la abertura de uno mismo. El expatriado, cualquiera que sea su motivo, busca las ventajas de su condición. Puede atraer un desdoblamiento de personalidad, elaborando un antifaz social totalmente dispar con lo que en realidad sufre, de defensa incómoda por contradicción o por confusión ante lo que parece. Añadiendo además que el recuerdo y la memoria pueden irrumpir vivamente por sorpresa, removiendo las entrañas del desertor.

- El loco por la escritura sueña con ser una sombra para desposar el agua. De esta unión nacen los libros.

Pero la sombra no es más que una mancha de memoria que el ojo percibe ${ }^{7}$.

3. SGARD, J. «C onclusions», en M OUN IER, J. (1986). Exil et litterature. Ellug. Equipe de Recherche sur le Voyage-U niversité des Langues et Lettres de G renoble.

4. En el artículo anteriormente citado, Sgard define el exilio metafórico como aquel exilio originado en el mundo cotidiano, provocando la necesidad de desarraigo.

5. Respuesta de Jan V ladislav en el artículo de GASS, W. «The Philosophical Significance of Exile», en G LAD, J. (ed.) (1990). Litterature in exile. D uke U niversity Press, Londres, p. 5.

6. Término utilizado y estudiado por H USSERL, E. (1991). La crisis de las ciencias europeas y la fenomenología transcendental. Barcelona: C rítica.

7. JABĖS, E. (1990). El libro de las preguntas. M adrid: Siruela, p. 82. 


\section{M ilan Kundera: el exilio en la novela}

Yo también bailé la rueda. Era primavera de 1948, los comunistas acababan de triunfar en mi país, los ministros socialistas y cristianos huyeron al extranjero y yo me cogía de la mano o de los hombros con otros estudiantes comunistas [... ] Luego un día dije al go que no tenía que haber dicho, me expulsaron del partido y tuve que salirme de la rueda.

Entonces tomé conciencia del significado mágico del círculo. Si nos alejamos de la fila, podemos volver a entrar en ella. La fila es una formación abierta. Pero el círculo se cierra y no hay regreso posible.

[... ] Igual que el meteorito despedido, volé yo también del círculo y sigo volando hasta hoy ${ }^{8}$.

D esde una catástrofe histórica, cualquier motivo puede provocar la aparición del orden de exilio como destierro. Para M ilan Kundera, su expulsión de la Checoslovaquia comunista (partido del que era militante) supuso el punzante sentimiento de nostalgia y de dolor frente a una situación absurda y risible. Su fórmula de exilio ha sido el salto fuera del círculo: el distanciamiento forzado por su entorno, sin esperanza de vuelta.

Pero esetiro despedido no solamente radica en su expatriación física. M ediante sus novelas escritas en el exilio, Kundera ha construido otra parteen la que puede moverse libremente sin miedo a posibles represalias políticas (aunque al gunas han acaecido por incomprensión). Puede volver a Praga a través de los personajes y sus circunstancias. En la elección de este novelista de seguir siendo novelista fuera de su tierra han surgido textos llenos de juego y sarcasmo debido a la injusticia sufrida y por eso, en sus relatos, calcula milimétricamente el punto exacto de una posible revancha. Precisamos: no en este mundo, sino en el mundo de la novela. La narración permite moderar velocidades, controlar gestos y respuestas pensadas, valorando consecuencias. Permite, en cierta medida, entender lo ocurrido $^{9}$, situarse en otros bandos. Por eso Kundera, como Ludvik ${ }^{10}$, no puedellevar a cabo su plan: las circunstancias han cambiado y surge el sentimiento de compasión. En sus historias se perciben todos los puntos de vista posibles de lo ocurrido, todas las posi bilidades de vida, en las que, finalmente, nadie ha sido feliz. N i expulsador ni expulsado. La historia no ha perdonado a nadie. Y entonces nos damos cuenta de la impotente sed de rencor. Como escribe Borges: «todo, entre los mortales, tiene el valor de lo irrecuperable y de lo azaroso» ${ }^{11}$.

Cuando somos víctimas de la sinrazón y la brutalidad, haciendo de nosotros seres aborrecibles, lo que aprendemos es que debemos vivir con ello. El perjudicado jamás podrá deshacer lo pasado. El dolor recibido es incurable. El olvido, imposible. Y en el caso de Kundera (así como el de algunos

\section{Kundera, M. (1993). El libro de la risa y el olvido. Barcelona: Seix Barral, p. 101.}

9. «[... ] no sólo la circunstancia histórica debe crear una situación existencial nueva, sino que la H istoria debe en sí misma ser comprendida y analizada como situación existencial.» KUndera, M . (1994). El arte de la novela. Barcelona: Tusquets, p. 49.

10. Personaje principal en Kundera, M . (1994). La broma. Barcelona: Seix Barral.

11. BORGES, J.L. (1995): «El inmortal», en El Aleph. M adrid: Alianza/Emecé, p. 23. 
escritores adheridos a la llamada «historia de la novela europea» ${ }^{12}$, como M usil o Rushdie) la ironía y la decepción acompañan sus relatos con una «tonalidad cercana a la melancolía depresi va» ${ }^{13}$, Ilena de escepticismo e incredulidad.

Emigrar de un país, separarse del círculo o desaparecer del ambiente habitual pueden convertirse en condiciones de supervivencia ante una nueva circunstancia. El extrañamiento de costumbres cotidianas y el recuerdo de episodios pasados no recuperables pueden provocar un constante sentimiento de aflicción, de dolor, adelantándose a la condena y a la interiorización. Física o mentalmente, un individuo se retrae del espacio confuso, liberándose de él mediante la huida y el silencio. Pero se trata de una decisión autónoma, obligándose a desaparecer y a esconderse de lo acontecido. Acaso este escondite pueda denominarse con la palabra cobardía, pero no olvidemos la valentía de soportar en la memoria la incomprensión infinita de lo advenido.

L'errance et l'émigration sont alors vécues comme une injustice, subies comme un exil imposé. L'émigration intérieure, que rien ne permet de distinguer de l'objection de conscience ou de l'opposition muette, représente peut-être une forme de l'exil ${ }^{14}$.

\section{Estar en otra parte}

El salto fuera del cárculo provoca el distanciamiento, la mirada contemplativa de lo forzosamente al ejado que permite aceptar las situaciones primariamente inexplicables. La imposibilidad de separarnos de nosotros mismos, de nuestras acciones y de los demás en la vida real para comprender sus circunstancias provoca una vivencia alternativa, un territorio paralelo que explique lo ocurrido: el mundo de ficción ${ }^{15}$.

Las ficciones proporcionan la base de las imágenes del mundo y los supuestos por los que guiamos nuestras acciones ${ }^{16}$.

El encuentro del escritor con la ficción, y concretamente en el espacio novelesco, permite este exilio eventual del mundo en el que vive, de manera que

12. Término utilizado por Kun DERA, M . (1994). El arte de la novela, Barcelona: Tusquets.

13. Expresión utilizada por $D$ aniel Bougnoux en su magnífico artículo «L'exil mode d'emploi chez Julio Cortazar et M ilan Kundera», en M oun IER, J. (1986). Exil et littérature, Ellug, U niversité de Recherche sur le Voyage, U niversité des Langes et Lettres de Grenoble. «Kundera écrit depuis un recul absolu, et non pas tactique, parce que c'est le recul ou l'exil de l'incroyance. D epuis cet observatoire il étudie l'île des croyants, leur monde clos, circulaire, enfantin. D e ce recul on ne revient pas: d'où la nostal gie constitutive de cette oeuvre sans retour possible.»

14. SGARD, J. «C onclusions», en M ounier, J. (1986). Op. cit., p. 292.

15. Ideas extraídas de Iser, W. «La ficcionalización: dimensión antropológica de las ficciones literarias》, en GARRID o D O m ín GUEZ, A. (comp.) (1997). Teorías de la ficción literaria. $M$ adrid: Arco/Libros.

16. I bídem, p. 46. 
ficción y realidad no son problema ni contradicción, sino formas complementarias, y el contemplador, que aspira a comprender mejor su situación, se aleja de ella y se ríe comicitivamente de su desesperación. Pero el acto de la escritura no usa la ficción como herramienta de desahogo, sino como espacio hallado para describir reflexivamente lo vivido. El retiro momentáneo del quehacer cotidiano vislumbra situaciones ocurridas no controladas por su immediatez. En cuestión de segundos, debemos decidir actos que pueden conllevar infinitas consecuencias. Se nos pide demasiado. Pero gracias a la escritura como supuesto lugar en otro mundo, podemos acercarnos a entender al gunas de la consecuencias que implican ciertas decisiones.

O saremos comparar el espacio ficcional con la propia experiencia, en el sentido que aquél permite averiguar reacciones probables ante una situación concreta. Sabemos, mediante un aprendizaje lento, el potencial de respuesta ante ciertas acciones. Y mediante la ficción aprendemos de otras posibilidades de vida que quizá nunca ocurrirán, pero que siempre es interesante conocer. Por si alguna vez nos encontramos en alguna de ellas. Como delata Borges, realidad y ficción son interdependientes y todas nuestras acciones son ficciones inventadas ${ }^{17}$. Lo ficticio depende de la realidad, pero no deriva de lo que hay ${ }^{18}$. El mundo de la novela está creado tanto por lo vivido como por aquello posible de ser vivido, un mundo supuesto, un como si. Este condicional surge cuando ya no podemos conocer más sobre lo ocurrido, cuando no es posible explicarnos lo ocurrido. Y por eso inventamos mediante la ficcionalización.

Como seres humanos estamos inmersos de posibilidades que pueden o no llevarse a cabo. C ada dirección, cada decisión que tomamos, es una posibilidad abierta y, a la vez, infinitas posibilidades cerradas, deshechadas. N uestras vidas dependen de ello. Esta responsabilidad cae violentamente sobre nosotros, cuyo peso sólo puede ser amortiguado por el desvelamiento de ese potencial perdido: el des-cubrimiento de posibilidades de vida en la narratividad de la novela.

Kundera [... ] da a entender que cualquier historia puede ser contada de diferentes maneras, y su sentido, comprendido de diversos modos, que la ficción elegida no es sino una posibilidad entre otras. Subraya así el carácter creativo de las historias y su estatuto ontológico de hipótesis; la estética de sus novelas ya no es la de la mímesis, la de una fiel reproducción de lo real; es una estética decididamente semiótica, es la semiótica de los mundos posibles ${ }^{19}$.

Lo afirmado hasta ahora presupone un enorme complejo al escritor exiliado que navega por las palabras en busca de una vida distinta a la vivida. La pérdida de amor propio, la inseguridad del mundo envolvente, el eterno errar

17. Entrevista a J.L. Borges. «El escritor europeo en el exilio», en KEARnEY, R. (1995). La paradoja europea. Barcelona: Tusquets, p. 133.

18. ISER, W. O p. cit., p. 59-60.

19. Chvatik, K. (1996). La trampa del mundo. M ilan Kundera, novelista. Barcelona: Tusquets, p. 15. 
por tierras desconocidas. Al fin, la patria del escritor alienado no reside en un estado geográfico, sino en una condición ficticia. El hecho de complementar su mundo cotidiano con la ficción permite el acercamiento de aquél, incontrolable e inestable, mediante un mundo aparte y a la vez adicional, lento y abierto. En la novela, el exiliado posee la esperanza de ser comprendido, de entender su condición de fugitivo para con los demás y, sobre todo, consigo mismo. El mundo de la novela se ha convertido en morada, en vuelta al hogar, después de deambular extraviado entre los vivos. El escritor encuentra en sus personajes ese otro yo al que ama más que a sí mismo, y esos actores permiten el acercamiento hacia una armonia entre el mundo en el que el escritor vive y ese otro mundo aparte, en el que viven sus otros yos ${ }^{20}$.

\section{C ondición judaica en la patria escrita}

Sabemos de escritores que han producido sus obras en lugares sórdidos y concurridos, como es el caso de Edmond Jabès, que escribió El libro de las pre guntas en el metro y «por supuesto había mucha gente alrededor $2^{21} 0$ el de Franz Kafka, que creaba sus historias por la noche, tras su ocupación como funcionario. El conocimiento de estas condiciones creativas permiten considerar otro tipo de exilio no presencial, inmaterial, que podría ser descrito como concentración en otro espacio, en un asedio interior y solitario, pero a la vez compartido por aquellos escritores que se encuentran fuera de lugar: un espacio común de encuentro de los desarrai gados que buscan su morada en el mundo.

[... ] no puedo evitar sentirme un poco perdido. No es mi paisaje, no es mi sitio, mi verdadero sitio. En cierto sentido, ahora vivo como históricamente lo han hecho los judíos. El libro se ha transformado en mi patria verdadera... prácticamente la única²2.

Los judíos sufren la deportación y el exilio ya en el siglo vi antes de Jesucristo. D e este exilio traen una escritura nueva y un texto escrito, considerado el instrumento mediante el cual Dios creó el mundo. Para O uaknin, los escribas definieron un texto que se convirtió en el «modelo mismo del mundo » ${ }^{23}$, un sitio distante del que vivimos pero donde se comprende el sentido de la vida en el mundo real. Es el descubrimiento del cómo vivir. Una revelación. Un espacio que regula el comportamiento de los hombres.

20. Entrevista a M ilan Kundera «La novela, madre de Europa», en Suplemento Libros El País, año VII, número 322, jueves 19 de diciembre de 1985, p. 3.

21. Auster, P. (1992). «Providence. Una conversación con Edmond Jabès», en El arte de hambre. Barcelona: Edhasa, p. 124.

22. Entrevista a Edmond Jabès en Auster, P. (1992). El arte del hambre. Barcelona: Edhasa, p. 124.

23. Entrevista a M .-A. O uaknin. «EI D ios de los judíos», en BotTÉRo, J.; O UAKN IN, M.-A.; M o IN GT, J. (1998). La historia más bella deD ios, ¿Q uién es el Dios dela Biblia? Barcelona: Anagrama, p. 52. 
Sin embargo, existe otro texto: el Talmud, el texto de la interpretación, de la pluralidad, de la infinitud de comentarios. «La necesidad del comentario es, como la necesidad poética, la forma misma de la palabra en el exilio»²4. Es la apertura del Texto hacia otros textos. Las fuentes de la escritura y de la lectura son inagotables, como su propio D ios. «Encerrarlo en una concepción única es lo mismo que matarlo o dejarlo morir $\aleph^{25}$. No hay nada definitivo, ni una patria fija. Solamente la esperanza en lo escrito aproxima al judío hacia su liberación prometida. Y ahí radica la vuelta inacabada del exilio. A lo largo de su historia, los judíos han interpretado su Texto originario sin llegar a tierra firme. El Lugar de la Torah se escapa. Como se escapa ese lugar del escritor ${ }^{26}$. La inquietud de la condición judía para encontrar su verdadero espacio provoca una actitud de búsqueda continua, sin descanso, a partir de una esperanza sedentaria.

Experiencia del Exilio, con todo lo que ello significa: infortunios de una existencia perseguida que establece en el corazón de cada uno ansiedad, inseguridad, desgracia y esperanza. [... ] H ay una «verdad del exilio» que implica una especie de vocación judía: ser judío significa estar destinado al exilio; la dispersión no tiene solamente un sentido negativo (la imposibilidad de lazos fijos con un grupo, un Estado [... ]; también tiene el sentido positivo de impedir la tentación de la unidad-identidad determinada de una vez para siempre ${ }^{27}$.

La vuelta del exilio no ha terminado. Rondan por tierras extrañas y vuelven a sus casas como extranjeros. El encuentro con moradas inhóspitas les retrae al punto de partida. La experiencia de destierro les obliga a refugiarse en la escritura. En su búsqueda perenne, el judío da la espalda al mundo. Y este espaldarazo, según Rosenzweig, se resuelve en uno de los mayores peligros para el hombre, atrayendo la angustia, la dureza y el orgullo. Pero eso no es problema para el judaísmo, sino para el propio individuo ${ }^{28}$, que debe vivir en el mundo cotidiano para estar en esa otra parte.

Se busca una morada para el descanso a cambio de la expulsión en vida sentenciada. Pero esa morada se ahuyenta. N o es ni escritura. «D esconfiad de

24. DeRrid A, J. (1989). La escritura y la diferencia. Barcelona: Anthropos, p. 93.

25. Bottéro, J.; O UAKNIN , M.-A.; M OINGT, J. (1998). O p. cit., p. 59.

26. Según el pensamiento judío, dos de sus condiciones identificativas están resumidas en los conceptos exilio y texto. El hombre, cuando se siente incomprendido e ignorado en su mundo cotidiano y se aísla brutalmente de su entorno familiar, puede recogerse en un mundo alejado pero más próximo a su estar. Así ocurre con la escritura. D e todos modos, esta relación de términos no debe interpretarse religiosamente. Las consideraciones presentadas no se resuelven en un contenido profeso, ortodoxo, sino que es simplemente una identificación. Tampoco debe derivarse de esta correlación un ensalzamiento de la condición judía frente a otras. Se trata tan solo de una posible analogía.

27. Bottéro, J.; O UAKNin, M.-A.; M oIngt, J. (1998). O p. cit., p. 82.

28. «Al judío le es necesario este acorazarse. Acorazarse es el último paso de la re-cordación, del enraizamiento en el propio sí-mismo del que extrae la fuerza de la vida eterna; así como aquella volatilización es para el cristiano la consecuencia necesaria de su salida, de su viaje sin trabas por el camino eterno». Ro SEN ZWEIG, F. (1997). La Estrella de la Redención. Salamanca: Sígueme, p. 477. 
las moradas. N o siempre son hospitalarias $»^{29}$. El exiliado convierte su mundo apartado en el escape de la palabra y parece encontrar en ella su casa alejada. Pero la herida del desgarramiento escuece en su curación y hasta puede llegar a cicatrizarse, o puede que también se abra en un descuido. Porque de la ilusión de hallar su hogar, el escritor, como el judío, vuelve a errar en lo escrito.

L ugar abierto, pluralidad de interpretaciones como posibilidades de vida, sin verdad definitiva, con sentidos lógicos y a la vez contrapuestos. El morador rompe el texto, lo «lee a estallidos» 30 , lo escribe riendo, sabiendo también que el texto se volatiliza burlándose del desterrado para distanciarse infinitamente. El infortunio de la libertad. Ser libre llevando a cuestas el temor de estar solo, en la angustia, pero con la esperanza de encontrar su casa en el «N o-Lugar $»^{31}$. Es La vida está en otra parte ${ }^{32}$. Es el «jamás has estado» AH Í, sino «En otro lugar por dentro $»^{33}$, ese mundo transmitido a los demás a través de lo escrito.

- O s he referido mis palabras. 0 s he hablado de la dificultad de ser judío, que se confunde con la dificultad de escribir; porque judaísmo y escritura no son sino una misma espera, una misma esperanza, un mismo desgaste ${ }^{34}$.

\section{Aprender en la errancia}

Sin embargo, ¿son todos los que escriben exiliados? ¿Tienen todos ellos semejantes distancias? ¿Es necesario ser escritor para alejarse de un mundo en el que no se encaja? La tentación de generalizar el suceso del desarraigo y la condición de apátrida a todo aquél que responda a circunstancias similares no deja de ser, sencillamente, peligrosa. Pensar en autores como Paul Auster o Edmond Jabès ha sido relativamentefácil por su condición judía. Pero no ocurre así con el novelista M ilan Kundera. Sin ninguna afinidad con esta tradición, la teoría de la novela del escritor checo parece alcanzar cierto arraigo hacia ella, hasta el punto de reconocer la esencia judaica como una de las bases más enraizadas en el pensamiento europeo ${ }^{35}$.

En un conocido texto de Walter Benjamin encontramos una distinción muy clara entre narrador y novelista que permitirá ubicar el sentido del escritor en el exilio y su aprendizaje en la escritura.

El narrador toma lo que narra de la experiencia, sea la propia o una que le ha sido transmitida. Y la transmite como experiencia para aquéllos que oyen su his-

29. JabÈs, E. (1984). «El regreso al libro», en El libro delas preguntas. M adrid: Siruela, p. 359.

30. Título de una de las obras de O UAKN IN, M.-A. (1992). Lire aux éclats. Éloge de la caresse. París: Seuil.

31. Término utilizado por D ERRIDA, J.: «La desconstrucción y lo otro», en KEARN EY, R. (1995). L a paradoja europea. Barcelona: Tusquets.

32. Título de una de las obras de M ilan Kundera.

33. Expresiones tomadas de J ABĖs, E. (1990). El libro de las preguntas. M adrid: Siruela, p. 350.

34. Íbídem, p. 126.

35. Véase su discurso de Jerusalén, «La novela y Europa», en El arte de la novela. Barcelona: Tusquets. 
toria. El novelista, en cambio, se ha aislado. El lugar de nacimiento de la novela es el individuo en su soledad, que ya no puede referirse, como a un ejemplo, a los hechos más importantes que lo afectan; que carece de orientación y que no puede dar consejo al guno. [... ] la novela nos hace saber cuál sea la profunda desorientación de los seres humanos ${ }^{36}$.

La experiencia parece ser el punto divergente entre ellos. Para Benjamin el que narra tiene suficientes razones como para poder dar consejos y educar a los lectores sobre cualquier motivo práctico. En cambio, la figura del novelista anda perdida en la búsqueda de sí mismo, en la palabra, mediante un discurso sin fundamento diestro, aislado de la experiencia pura. N o puede asesorar ni advertir. Su lejanía de lo real no le permite acercar su palabra a Io funcional. Lo extraviado aparece como condición del ser humano, sin ninguna instrucción aparente. Pero sí encontramos un cierto consuelo en la novela: una posible identificación entre la situación del lector con el texto, y en retroceso, con el autor. Además, el nacimiento de un relato aparece trasalguna experiencia vivida, emocional o manejada. Escribir a partir de un suceso acontecido (aunque se trate de un gesto o de una sola palabra) puede provocar el acercamiento lento y reflexivo de lo ocurrido. Se trata de un juego de posi ciones, de ese condicional «iqué hubiese ocurrido si... ?» que pertenece a la búsqueda de otra posibilidad de vida. Un cierto distanciamiento comprensivo, que no necesariamente justifique o perdone reacciones violentas ni amorales: «el territorio en el que se suspende el juicio moral »37. Un estar lejosque permita al que escribe vivir cerca de nuestro tiempo. Y que su escritura sea dada a los que quieran abrirse a su texto.

La vida de un escritor cobra sentido a través de lo que enuncia, escribe y puede ser transmitido de generación en generación ${ }^{38}$.

Porque el aprendizaje en el discurso novelesco no reside solamente en su alocución, sino también en la posición del lector que abre su mundo para permitir la entrada de espacios no conocidos, comprendiendo lo vivido a través de lo leído, de lo escrito, descubriendo otras posibilidades de vida desconocidas sin dejar de vivir la suya. Por lo tanto, la distinción que Benjamin recoge en su magnífico escrito depende, según nuestro punto de vista, de la apertura del lector frente al texto y de qué manera se define el concepto de experiencia.

Para que la lectura se resuelva en formación es necesario que haya una relación íntima entre el texto y la subjetividad. Y esa relación podría pensarse como experiencia, aunque entiendo experiencia de un modo particular. La expe-

36. Benjam IN , W. (1961). «EI narrador», en Sobre el programa de la filosofía futura y otros ensayos. C aracas: M onte Ávila, p. 193.

37. KUNDERA, M. (1994). Los testamentos traicionados. Barcelona: Tusquets, p. 15.

38. JabĖs, E. (1986). El libro delas preguntas. M adrid: Siruela, p. 45. 
riencia sería lo que nos pasa. No lo que pasa, sino lo que nos pasa. [... ] En la formación como lectura lo importante no es el texto sino la relación con el texto ${ }^{39}$.

En la ausencia del escritor, el libro habla por él. Y el lector escucha. También se aproxima a otra parte. Lo escrito vincula escritor y lector. Y el escritor es a la vez lector. Porque escucha en las palabras aquello que busca e interroga.

Aprender en la escucha, en el desarraigo. Estar en el libro. Estar en ese lugar, en esta «morada que está siempre amenazada» 40 .

39. LARRO SA, J. (1996). La Experiencia de la Lectura. Estudios sobre literatura y formación. Barcelona: Laertes, p. 18-19.

40. JABÈs, E. (1986). El libro de las preguntas. M adrid: Siruela, p. 37. Patria en el texto. Citaría incesantemente El libro de las preguntas: lugar en el exilio. 